\title{
Beobachtung des Encke'schen Cometen (1891 ...)
}

am I 2 zöll. Refractor der Sternwarte der Urania in Berlin.

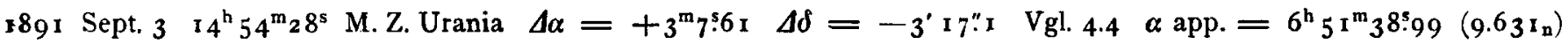

$$
\begin{aligned}
& \delta \text { app. }=+34^{\circ} 55^{\prime} \text { 1 1" I (0.699) Red. ad l. app. }=+0^{5} 79+0.5 \\
& \text { Vergleichstern (1891.0): } \alpha=6^{\mathrm{h}} 4^{8^{\mathrm{m}}} 3^{\mathrm{s}} \cdot 59 \quad \delta=+34^{\circ} 5^{8^{\prime}} 27^{\prime \prime} \cdot 7 \quad \mathrm{~W}_{2} 6^{\mathrm{h}} \times 3^{\mathrm{h}} 86
\end{aligned}
$$

Hieraus ergiebt sich in guter Uebereinstimmung mit einer Beobachtung vom Tage vorher die Correction der Ephemeride in A. N. 3048 zu etwa

$$
+12^{5}-0: 4 \text {. }
$$

Der Comet ist sehr hell und ausgebreitet, seine Helligkeit scheint rapide anzuwachsen; bis jetzt keine Spur von Kern erkennbar.

Berlin, Urania-Sternwarte, 189 I Sept. 5.

Gustav Witt.

\section{Ueber eine aussergewöhnliche Lichterscheinung auf der Sonne}

\author{
beobachtet auf der Urania-Sternwarte in Berlin.
}

Als ich am 2. August um $5^{\mathrm{h}} 20^{\mathrm{m}}$ das Sonnenbild vermittelst eines vierzölligen Refractors von Bamberg bei 90facher Vergrösserung auf einen weissen Schirm projicirte, bemerkte ich am rechten Rande einen grossen intensiv gelben Fleck, der die vorhandenen Fackeln an Helligkeit bedeutend übertraf. Um die Erscheinung, deren Intensität und Gestalt grossen Schwankungen unterworfen war, genauer zu betrachten, projicirte ich den betreffenden Theil des Sonnenrandes allein bei 180 facher Vergrösserung und konnte nun feststellen, dass der gelbe Fleck aus einer grossen Zahi von hellen gelben Linien und Punkten bestand, die selbst gleichmässig hell blieben, aber durch Veränderung ihrer Lage zu einander die Helligkeitsschwankungen veranlassten.

Berlin 189 I Sept. 4.
Als ich am 3. August um $5^{\mathrm{h}} \mathrm{o}^{\mathrm{m}}$ das Sonnenbild wiederum projicirte, konnte ich nur noch viele Fackeln bemerken, die auch schon am Tage vorher vorhanden waren; doch schien mir die Bewegung der Granulation eine aussergewöhnlich starke zu sein.

Eine ähnliche Beobachtung vom I 7 . und I 8 . Juni I 89 I hat Herr Trouvelot soeben in "L'Astronomie « veröffentlicht. Er glaubte spectroskopisch starke Eruptionen nachweisen zu können. Mir stand ein Spectroskop nicht zur Verfügung. Ich glaube indessen meine Beobachtungen, die ich von $5^{\mathrm{h}} 20^{\mathrm{m}}$ bis $6^{\mathrm{h}} 5^{\mathrm{m}}$ machte, mit der zweiten Phase der von Herrn Trouvelot gesehenen Erscheinung identificiren zu können.

Günther Maas, stud. math. et rer. nat.

\section{Todes-Anzeige.}

Am 2o. August d. J. verschied zu Heidelberg in einem Alter von nahe 70 Jahren der hochverdiente Astronom Franz Friedrich Ernst Brünnow. Er war am 18. Nov. I821 als Sohn des Geheimen Kanzleiraths am Königlichen Kammergericht, Johann Brünnow, und seiner ersten Ehegattin Wilhelmine geb. Weppler zu Berlin geboren. Dort besuchte er seit 1829 das Friedrich-Wilhelm.Gymnasium und seit 1839 die Universität, wo er die Vorlesungen von Dirksen, Lejeune-Dirichlet, Ohm und Steiner für Mathematik, von Encke für Astronomie und von Dove für Physik hörte. Auch Chemie, Philosophie und Philologie blieben ihm nicht fremd, indem er an den Vorlesungen der berühtesten Lehrer dieser Wissenschaften Theil nahm. Im April 1843 wurde er zum Doctor der Philosophie promovirt, nachdem er eine Abhandlung: »de attractione moleculari« herausgegeben hatte. Zusammen mit d'Arrest betheiligte er sich unter Encke's Leitung eifrig an den astronomischen Arbeiten der Berliner Sternwarte, wovon die sehr zahlreichen Mittheilungen in den Astronomischen Nachrichten vom 22. Bande an Zeugniss ablegen.

Im Frühjahr 1847 siedelte er nach Bilk bei Düsseldorf als Director der dortigen Sternwarte iuber. Von grösseren Arbeiten dieser Zeit ist zunächst die Abhandlung über den de Vico'schen Cometen zu erwähnen (Mémoire sur la Comète elliptique de de Vico, Amsterdam r 849), für welche er von der Amsterdamer Akademie die goldene Preismedaille erhielt. Dann fällt aber in die Zeit des Aufenthaltes in Bilk die Abfassung des Lehrbuches der Sphaerischen Astronomie, dessen erste Auflage mit einem Vorwort von Encke bei Dümmler in Berlin $185^{x}$ erschien. Dieses Lehrbuch, in späteren Auflagen bis zur vierten stetig verbessert und vervollständigt und ins Englische, Französische, Russische, Italienische und Spanische übertragen, hat vielleicht am meisten den Ruf Brünnow's begründet; es wurde bald und ist noch ein höchst schätzbares Hülfsmittel für die jüngeren Astronomen, denen es in gedrängter Form eine Anleitung zum Selbststudium bietet.

Nach dem im Herbst 185 I erfolgten Abgang von Professor Galle nach Breslau wurde Brünnow zum ersten Assistenten der Berliner Sternwarte berufen, in welcher Stellung er von November I85 I bis 1854 